\title{
Community utilisation and satisfaction with the community-based health planning and services initiative in Ghana: a comparative study in two system learning districts of the CHPS+ project
}

\author{
Margaret Kweku', Hubert Amu ${ }^{1 *}$ (D, Martin Adjuik', Fortress Yayra Aku', Emmanuel Manu',
}

Elvis Enowbeyang Tarkang ${ }^{1}$, Joyce Komesuor', Geoffrey Adebayor Asalu', Norbert Ndaah Amuna', Laud Ampomah Boateng' ${ }^{2}$, Justine Sefakor Alornyo ${ }^{2}$, Roland Glover ${ }^{2}$, Ayaga A. Bawah ${ }^{3}$, Timothy Letsa ${ }^{2}$, John Koku Awoonor-Williams ${ }^{4}$, James F. Phillips ${ }^{5}$ and John Owusu Gyapong ${ }^{6}$

\begin{abstract}
Background: To strengthen the implementation of the Community-based Health Planning and Services (CHPS) programme which is Ghana's key primary health care delivery strategy, the CHPS+ Project was initiated in 2017. We examined community utilisation and satisfaction with CHPS services in two System Learning Districts (SLDs) of the project.

Methods: This community-based descriptive study was conducted in the Nkwanta South Municipality and Central Tongu District of Ghana. Data were collected from 1008 adults and analysed using frequency, percentage, chisquare, and logistic regression models.

Results: While the level of utilisation of CHPS services was $65.2 \%$, satisfaction was $46.1 \%$. Utilisation was $76.7 \%$ in Nkwanta South and 53.8\% in Central Tongu. Satisfaction was also 55.2\% in Nkwanta South and 37.1\% in Central Tongu. Community members in Nkwanta South were more likely to utilise ( $A O R=3.17,95 \% \mathrm{Cl}=3.98-9.76)$ and be satisfied ( $A O R=2.77,95 \% \mathrm{Cl}=1.56-4.90)$ with CHPS services than those in Central Tongu. Females were more likely to utilise $(A O R=1.75,95 \% \mathrm{Cl}=1.27-2.39)$ but less likely to be satisfied $[\mathrm{AOR}=0.47,95 \% \mathrm{Cl}=0.25-0.90]$ with $\mathrm{CHPS}$ services than males. Even though subscription to the National Health Insurance Scheme (NHIS) was just 46.3\%, NHIS subscribers were more likely to utilise $(A O R=1.51,95 \% \mathrm{Cl}=1.22-2.03)$ and be satisfied ( $A O R=1.45,95 \% \mathrm{Cl}=0.53-$ 1.68) with CHPS services than non-subscribers.
\end{abstract}

(Continued on next page)

\footnotetext{
* Correspondence: hamu@uhas.edu.gh

${ }^{1}$ School of Public Health, University of Health and Allied Sciences, Hohoe, Ghana

Full list of author information is available at the end of the article
}

(c) The Author(s). 2020 Open Access This article is licensed under a Creative Commons Attribution 4.0 International License, which permits use, sharing, adaptation, distribution and reproduction in any medium or format, as long as you give appropriate credit to the original author(s) and the source, provide a link to the Creative Commons licence, and indicate if changes were made. The images or other third party material in this article are included in the article's Creative Commons licence, unless indicated otherwise in a credit line to the material. If material is not included in the article's Creative Commons licence and your intended use is not permitted by statutory regulation or exceeds the permitted use, you will need to obtain permission directly from the copyright holder. To view a copy of this licence, visit http://creativecommons.org/licenses/by/4.0/ The Creative Commons Public Domain Dedication waiver (http://creativecommons.org/publicdomain/zero/1.0/) applies to the data made available in this article, unless otherwise stated in a credit line to the data. 


\begin{abstract}
(Continued from previous page)
Conclusion: Ghana may not be able to achieve the goal of universal health coverage (UHC) by the year 2030 if current levels of utilisation and satisfaction with CHPS services persist. To accelerate progress towards the achievement of UHC with CHPS as the vehicle through which primary health care is delivered, there should be increased public education by the Ghana Health Service (GHS) on the CHPS concept to increase utilisation. Service quality should also be improved by the GHS and other stakeholders in Ghana's health industry to increase satisfaction with CHPS services. The GHS and the National Health Insurance Authority (NHIA) should also institute innovative strategies to increase subscription to the NHIS since it has implications for CHPS service utilisation and satisfaction.
\end{abstract}

Keywords: CHPS services, Utilisation, Satisfaction, Community members, System Learning District, Nkwanta South Municipality, Central Tongu District, Volta Region, Ghana

\section{Background}

Globally, critical public health concerns like morbidity and health inequity result from disparities in the availability, access, and utilisation of health services especially in low- and middle-income countries (LMICs) [1]. In response, the 1978 international conference on Primary Health Care (PHC) was organised at Almaty (formerly Alma-Ata) [2]. At the conference, PHC was identified as the key to attaining Universal Health Coverage (UHC) which was defined as essential health care made universally accessible to individuals and acceptable to them, through their full participation and at a cost that the community could afford [2]. This implies that the proximity, acceptance, satisfaction and perceived relevance of facilities within the catchment of communities, especially rural ones, is important in achieving UHC $[3,4]$. The Sustainable Development Goal (SDG) 3 which seeks to ensure healthy lives and promote wellbeing for all at all ages by the year 2030 [5, 6] is one of the strategies geared towards achieving UHC in LMICS.

Pursuant to the Almaty declaration, Ghana implemented various interventions towards achieving UHC. One of such interventions is the Community-based Health Planning and Services (CHPS) programme which was initiated in 1999 [7, 8]. The CHPS concept is a national health system initiative aimed at providing accessible primary health care through the reduction of physical and geographical limitations to health care accessibility in deprived communities in Ghana [9]. The role of CHPS in PHC implementation is thus to bring health services to local communities, develop sustainable volunteerism and community health action, empower vulnerable populations such as women, and enhance healthcare provider-community interaction [7]. Though not to desirable levels, the implementation of CHPS has led to reduced water-borne diseases, reduced infant and child mortalities through immunization, increased household involvement in the treatment of diarrhoea, and breastfeeding [9-11].
Even though it is recognised that community utilisation and satisfaction with health services are important indicators of health systems performance and are useful tools in predicting future service utilisation [12, 13], the utilisation and satisfaction with CHPS services have seen decreasing trends over past two decades [14-16] because CHPS services have been focused on the provision of clinical services and the construction of infrastructure to the detriment of community-based approaches which ensure that CHPS services are sent to the doorsteps of communities [17]. There was, therefore, the need to introduce interventions to improve its implementation and increase community utilisation and satisfaction with CHPS services. The result was the introduction of a National Program for Strengthening the Implementation of CHPS Initiative in Ghana (CHPS+) from which the current study was conducted. The purpose of the study was, therefore, to understand the level of community utilisation and satisfaction with CHPS services as part of the CHPS+ Project. Findings from the research will inform policymakers on measures needed to increase community ownership of CHPS as the key PHC intervention and its overall performance in improving health outcomes in Ghana.

\section{The CHPS+ project}

CHPS+ is a scale-up of the Ghana Essential Health Interventions Programme (GEHIP) [8]. It is a collaboration project by the GHS, the Mailman School of Public Health of the Columbia University, USA, the University of Ghana's Regional Institute of Population Studies, Ghana, the University of Health and Allied Sciences' (UHAS) School of Public Health (SPH), and the University for Development Studies (UDS) with funding from the Doris Duke Charitable Foundation, USA. As part of the project implementation, UHAS and UDS are to develop the capacity of frontline health workers through the development of short- and long-term training programmes in two administrative regions; Volta and Northern Regions respectively. 
In the Volta Region, the project primarily targets two administrative districts (Nkwanta South Municipality and Central Tongu District) selected by the regional health directorate of the GHS and labelled 'System Learning Districts' (SLDs). This, therefore, influenced the choice of the two districts for our study. The Volta Region was selected for the project as a result of having one of the highest underfive mortalities (61/1000) and fertility (4.8) rates in Ghana [4]. UHAS, the institution which led the current research is the project partner mandated to develop the capacity of frontline health workers in the Volta Region. The choice of UHAS for the project was due to its focus on problembased learning approach (christened 'vocational training programme') adopted in training students upon its establishment in 2011 by Act 828 of the Parliament of Ghana (became operational in 2012) [18].

The CHPS+ project has three implementation phases required for UHAS. Phase I comprises engaging in consultative meetings with the SLDs while Phase II entails planning and conducting stakeholder (frontline health workers and community members) engagements in the SLDs to identify frontline health workers' (CHOs, the staff at the sub-district level, and those at the district level) capacity development needs. The goal of phase II after identifying the training needs is to develop short and long-term capacity development curricular to help strengthen the implementation of CHPS by training the frontline health workers on the developed curricular.

To achieve the phase II expectations of the project after successfully executing the phase I, the university conducted a stakeholder engagement using a participatory approach to assess the capacity development needs of frontline health workers in the two SLDs. The result of that engagement was the development of a training curriculum which comprised 16 courses further divided into five modules. In August 2018, the university conducted training for the frontline workers on the Module One (UHAS+101: Community Entry and Organisation; UHAS+ 102: Cultural Competency in Health Care Delivery; and UHAS+103: Communicative Skills [Professional Communication]) of the curriculum in the two SLDs. At the end of the training which took place from 6th -11 th and 20th - 25th August respectively in Nkwanta South and Central Tongu, some common action points emanated which the trained frontline health workers and their respective district/municipal health directorates were expected to implement as the project is based on the implementation research approach. The action points included the need to increase community utilisation and satisfaction with CHPS services. With these action points in mind, 3 months after the training, the UHAS team conducted monitoring in selected communities in the two SLDs. The current research is the result of that monitoring which was conducted from 9th - 13th December 2018 in Nkwanta South and from 16th-20th December 2018 in Central Tongu. This study focuses on the part of the monitoring concerning community utilisation and satisfaction with CHPS services.

\section{Methods}

Study setting

This study was conducted in Central Tongu and Nkwanta South SLDs of the CHPS+ Project. Nkwanta South and Central Tongu are two of the 25 administrative districts in the Volta Region [19]. While Central Tongu is located in the southern coastal part of the region, Nkwanta South is situated at the Northern savannah belt [19]. The Volta Region is also one of the ten administrative regions in Ghana [19]. The region's total land area is $20,570 \mathrm{~km}^{2}$, representing $8.7 \%$ of the total land area of Ghana. The region has a total population of 2,549,256 with a growth rate of $2.5 \%$ as projected from the 2010 national population census. Out of this, males constituted 1,252,936 [19, 20].

The Central Tongu District has a total population of 71,302 a growth rate of $2.4 \%$ and the population covered by CHPS is 38,874 (54.5\%). The district has 500 communities with Adidome being the district capital. There is one district hospital, 4 health centres, and 1 private maternity home. The district has 18 demarcated CHPS zones out of which 15 zones are functional. The Nkwanta South Municipality has a population of 142, 602 with a growth rate of $3 \%$. There are 2 hospitals, 2 health centres and 1 maternity home. There are also 25 demarcated CHPS zones with 21 of them being functional CHPS zones [19]. A functional CHPS zone is one which has a CHPS compound which operates to support or facilitate emergency referrals besides the daily home visits and outreach activities [4]. Figure 1 presents a map of the study setting.

\section{Population and design}

A community-based descriptive cross-sectional study was carried out among adults aged 18 years and above in the two SLDs in December 2018. Community members were assessed using a pretested interviewer-administered semi-structured questionnaire. The assessment included utilisation and satisfaction with CHPS. Residents who had lived in the community for at least 6 months belonged to a household and consented were recruited to participate in the study.

\section{Sampling}

The sample size for the study was calculated using the Cochran [21] formula for sample size determination. The formula is given as $\mathrm{n}=\frac{(\mathrm{Z} \alpha / 2)^{2}(1-p) p}{d^{2}}$, The sample size for the study is determined below. 


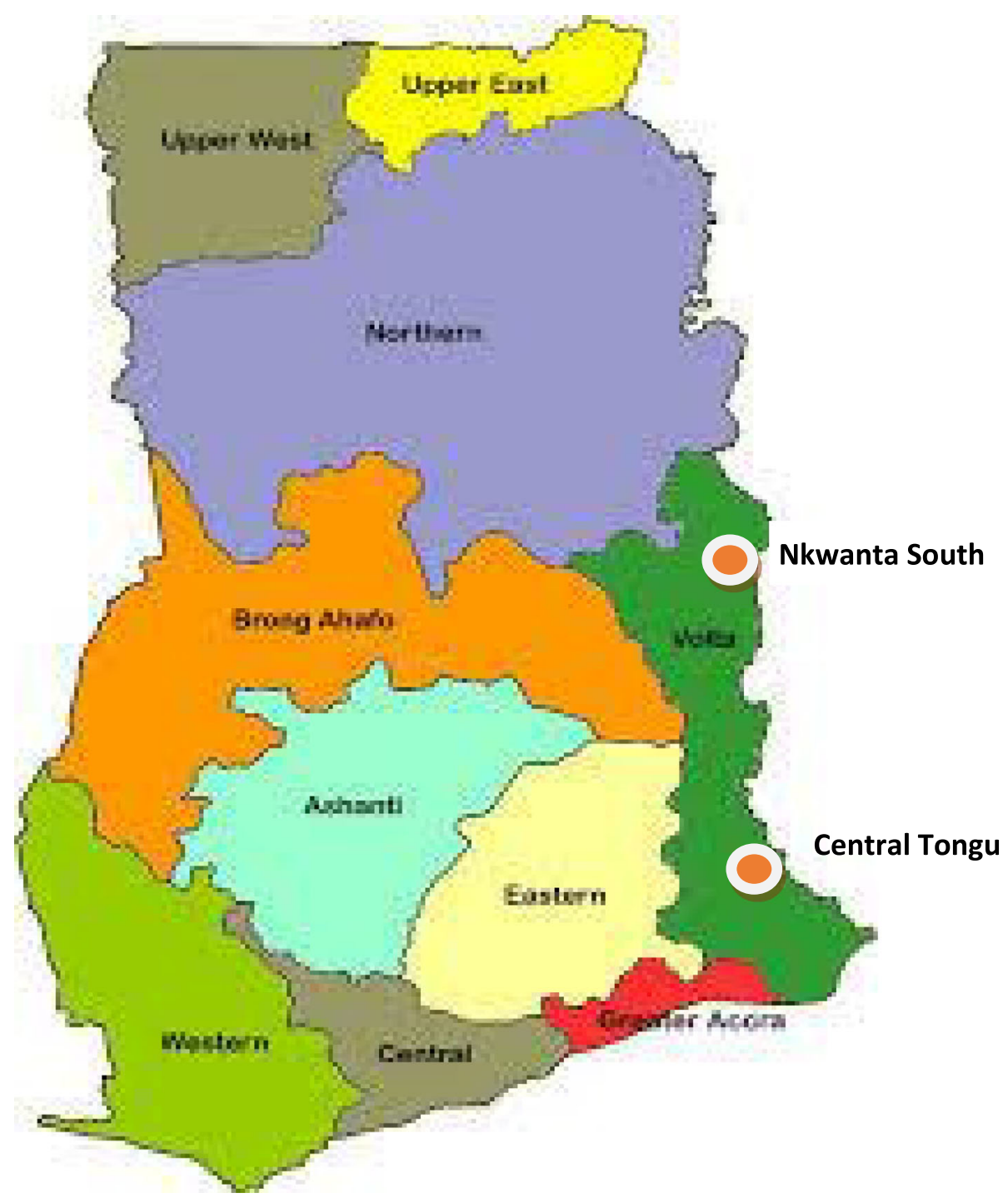

Fig. 1 Map of Study setting. Source: Created by the Authors

$$
\begin{aligned}
\mathrm{n} & =\frac{(\mathrm{Z} \alpha / 2)^{2}(1-p) p}{d^{2}}=\frac{1.962 \times 0.50 \times(1-0.50)}{0.052} \\
& =384.16=385
\end{aligned}
$$

Where: $\mathrm{n}=$ Required sample size, $\mathrm{Z}=$ Confidence level at $95 \%$ (standard value of 1.96 ), $\mathrm{P}=$ Prevalence in the population ( $50 \%$ default value for this study), $d=$ Level of Precision/margin of error of 0.05. Assuming a nonresponse rate of $10 \%$ of the sample size gives $38.5=39$. This gives a total of 424 . Thus, 405 for each district making a total sample of 848. However, a total of 1008 participants were studied, 504 from each study district.

A two-stage cluster sampling technique was used in selecting respondents for the study. The first stage involved the selection of communities. With this, six communities each were randomly selected out of the functional CHPS zones of the two clusters (the SLDs) using lottery method. At this stage, all the names of the communities in the functional zones of each SLD were written on pieces of paper. The papers were wrapped into small balls, placed in a container, and the container was thoroughly shaken. The first community was then selected. This process was repeated until the last community was selected in each district.

The WHO cluster random sampling was used at the community level to select participants. In the selection of households, the centre of the community was located, and a random household was chosen by spinning a bottle. The first household in the direction where the bottle pointed then became starting household surveyed. Every other 5th household in that direction was then included in the data collection. The number 5 was used based on the sampling fraction derived. A household is defined as a group of people who live under the same roof and eat 
together. In each household, a male, female, or both (18+ years of age) were interviewed once present.

\section{Data collection}

We developed a structured questionnaire and used it as the main instrument for data collection (See Additional File 1). The questionnaire was divided into three sections; 100, 200, and 300 . The first section focused on the socio-demographic characteristics of the respondents. They were age, sex, religion, marital status, ethnicity, educational level, occupation, average monthly income, and National Health Insurance Subscription status. The second section focused on CHPS services utilisation among community members and was made up of seven variables; home visit, family planning, antenatal care, skilled delivery, post-natal (PNC) services, child welfare clinic and immunisation as well as treatment of minor ailments. The respondents were asked to select the various CHPS services they utilised in the 6 months preceding the survey. The third section also focused on community members' satisfaction with the CHPS services received in the second section. In this section, respondents were required to indicate their level of satisfaction with the services on a Likert scale of very satisfied (coded as 4), satisfied (coded as 3), not satisfied (coded as 2) and not at all satisfied (coded as $1)$. An overall dichotomous satisfaction index variable of satisfied (1) and not satisfied (0) was computed using the composite scores of the various variables. To achieve the index variable, a mean scored of 11.08 was generated as the cut-off point. Those who scored above the mean were considered 'satisfied'. This variable was then used in running the logistic regression analyses. Reliability analysis was done to determine the appropriateness of the items of the instrument in measuring the expected outcomes, using a Cronbach's alpha analysis. A Cronbach's alpha coefficient of 0.90 derived indicated that the instrument was reliable based on Taber's interpretation [22].

Eighteen research assistants from the School of Public Health $(\mathrm{SPH})$ of UHAS were trained as field assistants for 2 days on the data collection tools. Four lecturers from SPH-UHAS also served as the supervisors of these field assistants. During the training, the field assistants were informed about the purpose of the study and taken through all the data collection tools. The training was done to ensure that all data collectors understood how to ask questions to enable the respondents to provide appropriate answers. On the second day of the training, pre-testing of the instruments was done in one community in the Hohoe Municipality which is also one of the 25 administrative districts of the Volta Region. This was done to enable the research team to know how the respondents understood and responded to the questions. No major changes were, however, done on the tools after the pre-testing.
Permission for the data collection was sought from the health directorates of the two SLDs through letters. Meetings were also held with opinion leaders of the sampled communities to seek their consent for the study. Informed consent was sought from each participant before questionnaires were administered. Names of participants and their communities were not collected in the questionnaires instead, codes were used as unique identifiers.

\section{Data analysis}

Filled questionnaires were checked for completeness and corrected on the field. The data were then entered into Epi-data version 3.1 and exported into Stata/SE version 14.0 for analysis. Continuous variables were reported as mean \pm standard deviation. Categorical variables were reported as proportions. Chi-square test was used to determine the association between variables of interest. Statistical significance was considered at $p<0.05$. Logistic regression models were used to determine the strength of associations among variables of interest. Two regression models (I [bivariable] and II [multivariable]) were done.

\section{Results}

Socio-demographic characteristics of respondents

Table 1 presents the socio-demographic characteristics of respondents. A total of 1008 respondents from Central Tongu and Nkwanta South SLDs were involved in the study. The mean age was $39.2 \pm 14.65$. The majority $(56.3 \%)$ of respondents were females. Most $(81.8 \%)$ were Christians and married/Co-habiting (81.0\%). Ewes were the most (64.4\%) represented ethnic group in the two SLDs. Respondents constituting $34.4 \%$ attained Junior High School (JHS) level of education, while $28.4 \%$ had no formal education. Majority of the respondents were farmers $(62.1 \%)$. The average monthly income of $60.3 \%$ of our respondents ranged from $\mathrm{GH} 100-499$. GH\& (The Ghana Cedi) is the official currency of Ghana. Respondents who were subscribers to the NHIS also constituted $46.3 \%$.

\section{Utilisation of CHPS services}

Figure 2 presents the CHPS services utilisation by respondents in the two SLDs. The utilisation of home visits, Family Planning (FP), Antenatal Care (ANC), as well as Child Welfare Clinic (CWC) and immunisation services were significantly higher in Nkwanta South than Central Tongu $(p<0.001, p<0.01, p<0.01$, and $p<$ $0.001)$ respectively.

Figure 3 presents the level of utilisation of CHPS as an aggregation of all the seven utilisation variables. Overall, the level of utilisation of CHPS was $65.2 \%$. While the level of utilisation of CHPS was $76.7 \%$ in Nkwanta South, it was $53.8 \%$ in Central Tongu. 
Table 1 Background Characteristic of respondents

\begin{tabular}{|c|c|c|c|}
\hline \multirow[t]{2}{*}{ Variable } & \multicolumn{2}{|l|}{ District } & \multirow{2}{*}{$\begin{array}{l}\text { Total } \\
{[N=1008] N(\%)}\end{array}$} \\
\hline & Central Tongu [N = 504] n (\%) & Nkwanta South [N= 504] n (\%) & \\
\hline \multicolumn{4}{|l|}{ Sex } \\
\hline Male & 231(45.8) & 210(41.7) & $441(43.7)$ \\
\hline Female & $273(54.2)$ & 294(58.3) & $567(56.3)$ \\
\hline \multicolumn{4}{|c|}{ Mean age (in years) $39.2 \pm 14.65$} \\
\hline \multicolumn{4}{|c|}{ Age group (in years) } \\
\hline$<30$ & 156(31.0) & $140(27.8)$ & 296(29.4) \\
\hline $30-39$ & $135(26.8)$ & $135(26.8)$ & $270(26.8)$ \\
\hline $40-49$ & $95(18.8)$ & $107(21.2)$ & $202(20.0)$ \\
\hline $50+$ & 118(23.4) & $122(24.2)$ & $240(23.8)$ \\
\hline \multicolumn{4}{|l|}{ Religion } \\
\hline Christianity & $451(89.5)$ & $373(74.0)$ & $824(81.7)$ \\
\hline Islam & 19(3.8) & $26(5.2)$ & $45(4.5)$ \\
\hline African Traditional & $34(6.7)$ & 105(20.8) & 139(13.8) \\
\hline \multicolumn{4}{|l|}{ Marital Status } \\
\hline Married/Co-habiting & $404(80.1)$ & 413(81.9) & $817(81.0)$ \\
\hline Divorced/Separated & $17(3.4)$ & $21(4.2)$ & 38(3.8) \\
\hline Widowed & $16(3.2)$ & $27(5.4)$ & $43(4.3)$ \\
\hline Never married & $67(13.3)$ & $43(8.5)$ & 110(10.9) \\
\hline \multicolumn{4}{|l|}{ Ethnicity } \\
\hline Ewe & 496(98.4) & 154(30.5) & $650(64.5)$ \\
\hline Akan & $4(0.8)$ & $31(6.2)$ & $35(3.5)$ \\
\hline Guan & $1(0.2)$ & $258(51.2)$ & $259(25.7)$ \\
\hline Others & $3(0.6)$ & $61(12.1)$ & $64(6.3)$ \\
\hline \multicolumn{4}{|l|}{ Educational level } \\
\hline None & 109(21.6) & $177(35.1)$ & $286(28.4)$ \\
\hline Primary & $107(21.2)$ & $90(17.8)$ & 197(19.5) \\
\hline JHS & 191(37.9) & 156(31.0) & $347(34.4)$ \\
\hline SHS & 70(13.9) & $62(12.3)$ & 132(13.1) \\
\hline Tertiary & $27(5.4)$ & 19(3.8) & $46(4.6)$ \\
\hline \multicolumn{4}{|l|}{ Occupation } \\
\hline Unemployed & $40(7.9)$ & $35(6.9)$ & $75(7.4)$ \\
\hline Trader & $65(12.9)$ & $74(14.7)$ & $139(13.7)$ \\
\hline Farmer & $319(63.3)$ & $307(60.9)$ & $626(62.1)$ \\
\hline Tradesman & $27(5.4)$ & $39(7.7)$ & $66(6.6)$ \\
\hline Seamstress/hair dresser & $24(4.8)$ & $27(5.4)$ & $51(5.1)$ \\
\hline Civil servant & $29(5.7)$ & $22(4.4)$ & $51(5.1)$ \\
\hline \multicolumn{4}{|l|}{ Income (in GHC) } \\
\hline Very low $(<100)$ & 109(21.6) & $129(25.6)$ & $238(23.7)$ \\
\hline Low (100-499) & 297(59.2) & $310(61.5)$ & $607(60.3)$ \\
\hline High (500-999) & $60(12.0)$ & $46(9.1)$ & $106(10.5)$ \\
\hline Very high ( $\geq 1000)$ & $36(7.2)$ & 19(3.8) & $55(5.5)$ \\
\hline
\end{tabular}


Table 1 Background Characteristic of respondents (Continued)

\begin{tabular}{llll}
\hline Variable & District & & Total \\
\cline { 2 - 4 } & Central Tongu $[N=504] \mathrm{n}(\%)$ & Nkwanta South $[N=504] \mathrm{n}(\%)$ & {$[N=1008] \mathrm{N}(\%)$} \\
\hline NHIS Status & & $243(48.2)$ & $467(46.3)$ \\
Subscriber & $224(44.4)$ & $261(51.8)$ & $541(53.7)$ \\
Non-subscriber & $280(55.6)$ & & \\
\hline
\end{tabular}

\section{Influence of socio-demographic characteristics on the utilisation of CHPS}

Table 2 presents the association between sociodemographic characteristic and the odds of the utilisation of CHPS. Respondents in Nkwanta South Municipality were 3.17 times significantly $[95 \% \mathrm{CI}=3.98-9.76$, $p<0.001$ ] more likely to utilise CHPS compared with those in the Central Tongu District. Females were 1.75 times significantly $[95 \% \mathrm{CI}=1.27-2.39, p<0.01]$ more likely to utilise CHPS than males. Respondents aged 30$39,40-49$ and 50 years and above were 18\% [AOR = $0.82,95 \% \mathrm{CI}=0.54-1.26], 36 \%[\mathrm{AOR}=0.64,95 \% \mathrm{CI}-0.40]$ and $51 \%[\mathrm{AOR}=0.49,95 \% \mathrm{CI}=0.31-0.79]$ respectively less likely to utilise CHPS compared with those aged less than 30 years.

Respondents who were never married were 50\% significantly less likely $[\mathrm{AOR}=0.50,95 \% \mathrm{CI}=0.30-0.83, p<$ 0.01] to utilise CHPS than those who were married. Those who attained SHS or tertiary educational levels were $23 \%[\mathrm{AOR}=0.77,95 \% \mathrm{CI}=0.64-1.26]$ and $61 \%$ [AOR $=0.39,95 \% \mathrm{CI}=0.13-1.22]$ respectively less likely to utilise CHPS as compared with those with no formal education and. Subscribers to the NHIS were, however,
1.51 times more likely to utilise CHPS compared with those who were non-subscribers [95\% CI $=1.22-2.03]$.

\section{Satisfaction with CHPS}

Figure 4 presents respondents' satisfaction with the various CHPS services by district. Satisfaction with the treatment of minor ailments was significantly higher in Nkwanta South than Central Tongu $(p<0.01)$. No significant differences were, however, observed in the satisfaction of respondents with home visit, FP, ANC, skilled delivery, PNC as well as CWC and immunisation between the two SLDs.

Figure 5 presents the level of satisfaction with CHPS as an aggregation of all the satisfaction variables. Overall, the level of satisfaction with CHPS was $46.1 \%$. While the level of satisfaction with CHPS was $55.2 \%$ in Nkwanta South, it was $37.1 \%$ in Central Tongu.

\section{Influence of socio-demographic characteristic and utilisation of CHPS on satisfaction with CHPS}

Table 3 presents the influence of socio-demographic characteristic and utilisation of CHPS on satisfaction with CHPS. Community members in Nkwanta South

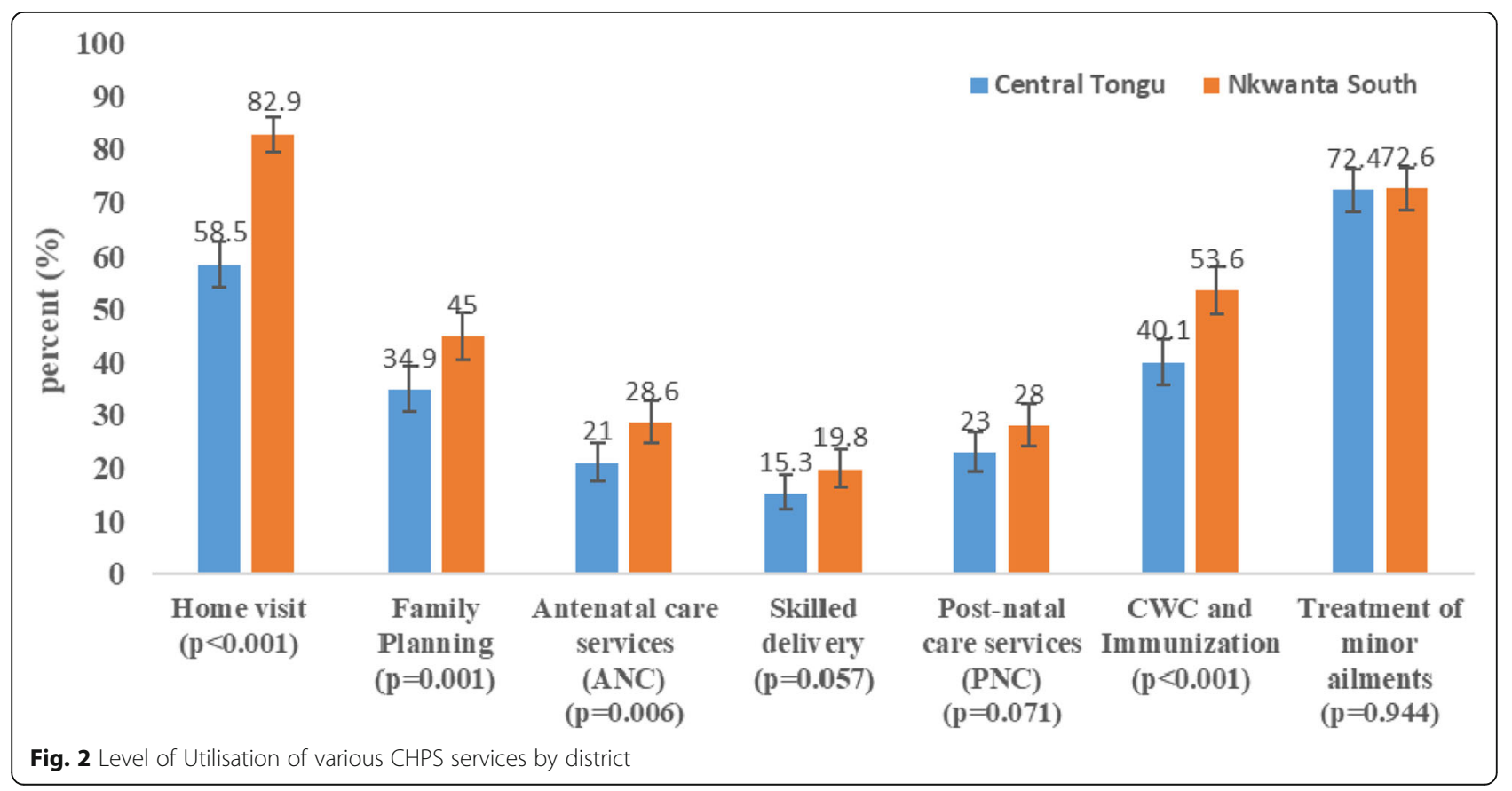




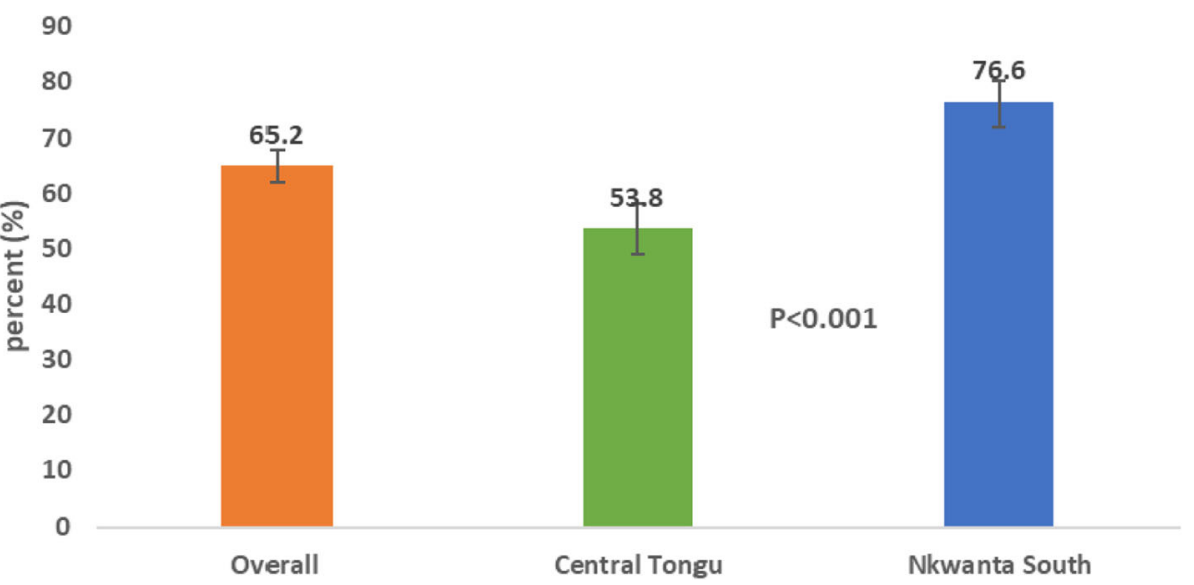

Fig. 3 Level of utilisation of CHPS services overall and by district

Municipality were 2.77 times $[95 \% \mathrm{CI}=1.56-4.90, p<$ $0.001]$ more likely to be satisfied with CHPS services compared with those in the Central Tongu District. Respondents who were aged 50 years and above were 3.10 times more likely to be satisfied with CHPS services compared with those aged less than 30 years $[\mathrm{AOR}=3.10,95 \% \mathrm{CI}=$ 1.25-7.68), $p=0.014]$. Females and civil servants were $53 \%$ [AOR $=0.47,95 \% \mathrm{CI}=0.25-0.90, p<0.05]$ and $99.6 \%$ $[\mathrm{AOR}=0.04,95 \% \mathrm{CI}=0.0-0.67, p<0.05]$ less likely to be satisfied with CHPS services compared with males and those who were unemployed respectively.

Respondents who utilised home visit, family planning, antenatal care services were also $27.47[95 \% \mathrm{CI}=11.51-$ 65.54, $p<0.001], 23.54[95 \% \mathrm{CI}=11.97-46.29, p<0.001]$ and $52.30[95 \% \mathrm{CI}=14.56-187.77, p<0.001]$ times respectively more likely to be satisfied with CHPS services compared with those who did not utilise those services. Respondents who utilised PNC, CWC and immunisation, as well as services related to the treatment of minor ailment were $9.47[95 \% \mathrm{CI}=2.87-31.19, p<0.001], 25.95$ $[95 \% \mathrm{CI}=12.71-53.00, p<0.001]$ and $15.76[95 \% \mathrm{CI}=$ $7.22-34.43, p<0.001]$ times more likely to be satisfied with CHPS services compared with those who did not utilise them respectively.

\section{Discussion}

This study examined community utilisation and satisfaction with CHPS services in two system learning districts of the CHPS+ Project in Ghana. We found that the level of utilisation of CHPS services in the two SLDs of our study was lower than the $73 \%$ reported by Wiru et al. [15] in the Kintampo North Municipality of Ghana. Comparatively, we realised in our study that the level of utilisation was higher in the Nkwanta South Municipality than in the Central Tongu District. Community members in Nkwanta South Municipality were more likely to utilise CHPS services compared with those in the Central Tongu District. This finding may be because Nkwanta South was the first district to pilot CHPS in the Volta Region after the Navrongo experiment in 1999 [23]. Therefore, community members might have been used to CHPS. Besides, the comparatively poorer road network in Nkwanta South coupled with the wider geographical space the municipality covers, makes it difficult for many communities to access health services at the Nkwanta South Municipal Hospital and the St. Joseph's Hospital which are both located at Nkwanta, the Municipal Capital [17, 24]. Meanwhile, CHPS is provided in virtually all the communities of the municipality thus becomes the readily utilised health service for the people.

While Central Tongu is located in the southern coastal part of the Volta Region, Nkwanta South is situated at the Northern savannah belt [19]. Our finding of lower utilisation of CHPS services in Central Tongu may be related to previous findings that people in the southern coastal areas of Ghana usually experience a multiplicity of healthcare facilities and services [25]. Their perception of the quality of services including CHPS, therefore, easily becomes negative due to the awareness that they can always change their service providers/health facilities whenever they feel dissatisfied with services utilised [26]. The lower level of utilisation realised in the Central Tongu District has negative implications for Ghana's attainment of UHC which all developing countries are required to achieve by the year 2030 [27].

We found that females were more likely to utilise CHPS services than males. This is similar to findings from Kintampo where females were 6 times more likely to use CHPS services than males [15]. The possible reasons could be that apart from family planning services, most CHPS services such as ANC, CWC, PNC, and skilled delivery, are female-focused. Additionally, research has shown that females by nature exhibit better health-seeking behaviour than males and this may be 
Table 2 Influence of socio-demographic characteristic and the utilisation of CHPS

\begin{tabular}{|c|c|c|c|c|c|}
\hline \multirow[t]{2}{*}{ Variables } & \multicolumn{2}{|l|}{ Utilisation } & \multirow{2}{*}{$\begin{array}{l}\text { Chi-square } \\
\text { (p-value) }\end{array}$} & \multirow[t]{2}{*}{ COR $(95 \%$ Cl) $\boldsymbol{p}$-value } & \multirow[t]{2}{*}{ AOR $(95 \% \mathrm{Cl}) \boldsymbol{p}$-value } \\
\hline & Low Utilisation & High Utilisation & & & \\
\hline District & & & $57.80(<0.001)$ & & \\
\hline Central Tongu & $233(66.4)$ & 271(41.3) & & Ref. & Ref. \\
\hline Nkwanta South & 118(33.6) & $386(58.7)$ & & $2.81(2.14 ; 3.68)<0.001$ & $3.17(2.35 ; 4.25)<0.001$ \\
\hline Sex & & & $41.67(<0.001)$ & & \\
\hline Male & 202(57.6) & 239(36.4) & & Ref. & Ref. \\
\hline Female & 149(42.4) & 418(63.6) & & $2.37(1.81 ; 3.08)<0.001$ & $1.75(1.27 ; 2.39) 0.001$ \\
\hline Age group & & & $8.06(0.045)$ & & \\
\hline$<30$ & $95(27.1)$ & 201(30.6) & & Ref. & Ref. \\
\hline $30-39$ & $83(23.7)$ & $187(28.5)$ & & $1.06(0.74 ; 1.51) 0.729$ & $0.82(0.54 ; 1.26) 0.370$ \\
\hline $40-49$ & $73(20.8)$ & 129(19.6) & & $0.83(0.57 ; 0.57) 0.349$ & $0.64(0.40 ; 1.00) 0.053$ \\
\hline $50+$ & $100(28.4)$ & $140(21.3)$ & & $0.66(0.46 ; 0.46) 0.022$ & $0.49(0.31 ; 0.79) 0.003$ \\
\hline Marital status & & & $21.48(<0.001)$ & & \\
\hline Married/Co-habiting & $265(75.5)$ & $552(84.0)$ & & Ref. & Ref. \\
\hline Divorced/Separated & $11(3.1)$ & $27(4.1)$ & & $1.17(0.57 ; 2.41) 0.653$ & $1.29(0.61 ; 2.78) 0.499$ \\
\hline Widowed & $15(4.3)$ & $28(4.3)$ & & $0.89(0.47 ; 1.71) 0.739$ & $0.91(0.45 ; 1.85) 0.794$ \\
\hline Never married/ never Co-habited & $60(17.1)$ & $50(7.6)$ & & $0.40(0.26 ; 0.59)<0.001$ & $0.50(0.30 ; 0.83) 0.007$ \\
\hline Education & & & $42.15(<0.001)$ & & \\
\hline None & $98(27.9)$ & 188(28.6) & & Ref. & Ref. \\
\hline Primary & $57(16.2)$ & $140(21.3)$ & & $1.28(0.57 ; 2.41) 0.218$ & $1.53(0.99 ; 2.36) 0.052$ \\
\hline JHS & $100(28.5)$ & $247(34.6)$ & & $1.28(0.57 ; 2.41) 0.142$ & $0.65(1.12 ; 2.43) 0.011$ \\
\hline SHS & $65(18.5)$ & $67(10.2)$ & & $0.53(0.35 ; 0.82) 0.004$ & $0.77(0.46 ; 1.26) 0.296$ \\
\hline Tertiary & $31(8.9)$ & $15(2.3)$ & & $0.25(0.12 ; 0.48)<0.001$ & $0.39(0.13 ; 1.22) 0.077$ \\
\hline Occupation & & & $36.79(<0.001)$ & & \\
\hline Unemployed & $31(8.8)$ & $44(6.7)$ & & Ref. & Ref. \\
\hline Trader & $39(11.1)$ & $100(15.2)$ & & $1.81(1.00 ; 3.25) 0.049$ & $1.27(0.65 ; 2.49) 0.475$ \\
\hline Farming & $199(56.7)$ & $427(65)$ & & $1.51(0.93 ; 2.46) 0.098$ & $1.45(0.81 ; 2.64) 0.211$ \\
\hline Trace Person & $36(10.3)$ & $30(4.6)$ & & $0.58(0.30 ; 1.14) 0.118$ & $0.49(0.22 ; 1.08) 0.078$ \\
\hline Seamstress/Hairdresser & $14(4.0)$ & $37(5.6)$ & & $1.86(0.86 ; 4.01) 0.113$ & $1.01(0.43 ; 2.36) 0.976$ \\
\hline Civil Servant & $32(9.1)$ & $19(2.9)$ & & $0.41(0.20 ; 0.86) 0.019$ & $1.10(0.37 ; 3.32) 0.854$ \\
\hline NHIS Status & & & $10.65(<0.01)$ & & \\
\hline Non-subscriber & $213(60.7)$ & $328(49.9)$ & & Ref. & Ref. \\
\hline Subscriber & 138(39.3) & $329(50.1)$ & & $1.54(1.18 ; 2.01) 0.001$ & $1.51(1.22 ; 2.03) 0.318$ \\
\hline
\end{tabular}

due to gender role differentiations including social class, education, and vulnerability to ill-health [28].

Our findings show that NHIS subscribers were more likely to utilise CHPS services than non-subscribers. This might be due to the financial protection which the scheme offers its subscribers $[28,29,30]$. This is because once subscribers pay affordable annual premiums, they can utilise health services covered by the scheme without paying anything at the point of service delivery [26, 29]. Also, indigents, pregnant women, Social Security and National Insurance Trust (SSNIT) pensioners and active contributors, as well as children younger than 18 years do not pay the annual premiums for subscribing to the scheme [30, 31]. All these groups of people in the community are, thus, likely to find it easier utilising CHPS services than those who have to pay out of pocket to utilise such services due to their non-subscription status.

The level of satisfaction recorded in our study was lower than the $65.8 \%$ satisfaction level of CHPS services recorded by Wood and Esena [16] in the Komenda Edina Eguafo Abrem Municipality.

While the level of satisfaction was high in Nkwanta South, it was low in Central Tongu. The variation in the 


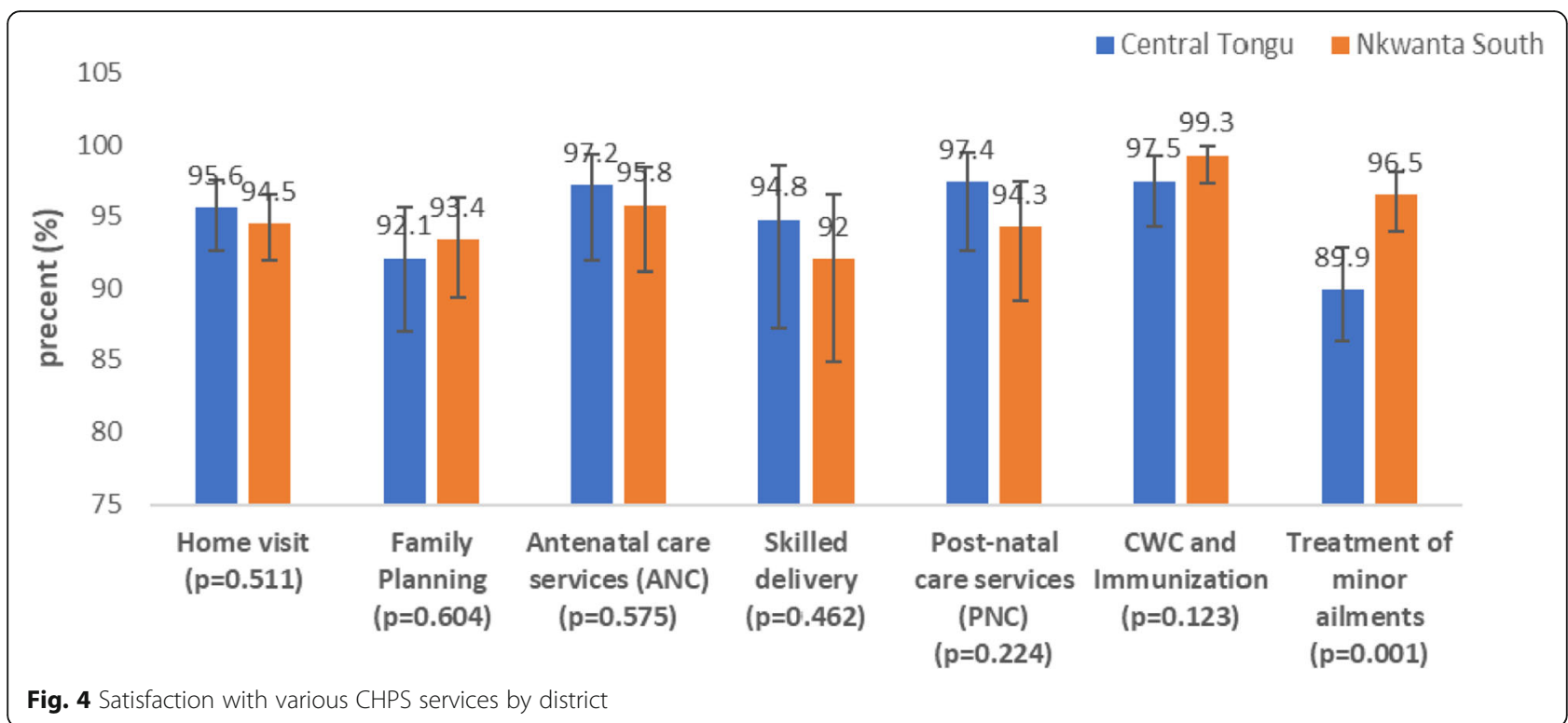

level of satisfaction observed between the two districts illustrates the role of geographical antecedents discussed earlier and the deplorable nature of roads in the Nkwanta South Municipality which restrict community members' access to CHPS and the fact that they are not able to have alternatives to CHPS services [32].

Our study also found that females were less likely to be satisfied with CHPS services than males. The possible reasons could be that as the main users of CHPS services such as family planning, $\mathrm{ANC}, \mathrm{CWC}, \mathrm{PNC}$ and skilled delivery they are more likely to encounter the challenges associated with CHPS implementation. This finding is congruent to the postulation by Azha et al. [33] that females were less likely to be satisfied with primary health care services such as CHPS.

\section{Strengths and limitations}

Our study is the first effort at understanding the levels of community utilization and satisfaction with CHPS in Ghana. This is a strength because, even though CHPS was implemented to address the health needs of Ghanaian residents by bringing health care to the doorsteps of communities, there have not been studies examining the extent to which this goal has been achieved. Our findings are, therefore, essential in informing policy directions regarding community ownership of CHPS implementation. A limitation of our study is the fact that we depended on verbal reports of community members. The accounts given by the study participants regarding their utilization and satisfaction with CHPS services might have, therefore, suffered response and recall biases.

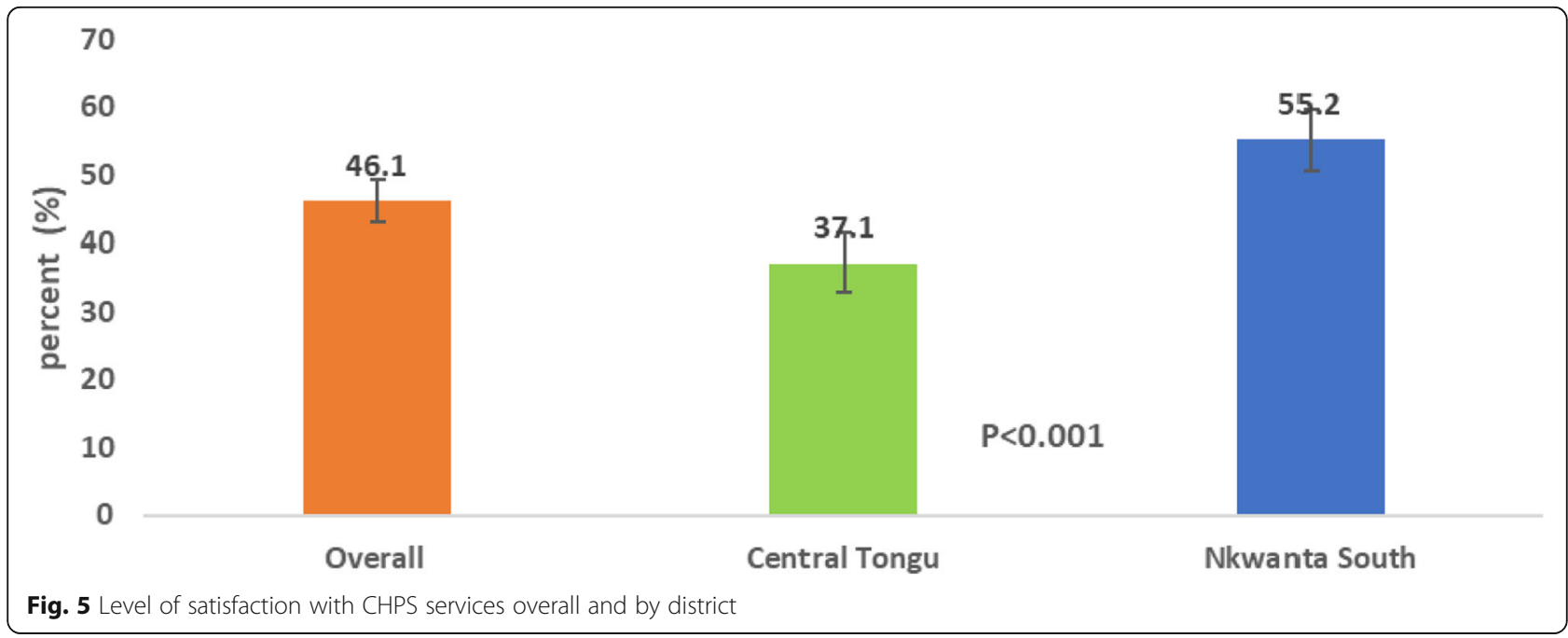


Table 3 Influence of Socio-demographic characteristics and utilisation on satisfaction with CHPS

\begin{tabular}{|c|c|c|c|c|c|}
\hline \multirow[t]{2}{*}{ Variables } & \multicolumn{2}{|l|}{ Level of Satisfaction } & \multirow{2}{*}{$\begin{array}{l}\text { Chi-square } \\
\left(x^{2}\right)(\boldsymbol{p} \text {-value })\end{array}$} & \multirow[t]{2}{*}{ COR $(95 \% \mathrm{Cl}) \boldsymbol{p}$-value } & \multirow[t]{2}{*}{ AOR $(95 \% \mathrm{Cl}) \boldsymbol{p}$-value } \\
\hline & $\begin{array}{l}\text { Not satisfied }[\boldsymbol{N}=543] n \\
(\%)\end{array}$ & $\begin{array}{l}\text { Satisfied }[\boldsymbol{N}=465] \mathrm{n} \\
(\%)\end{array}$ & & & \\
\hline District & & & $\begin{array}{l}33.05(< \\
0.001)\end{array}$ & & \\
\hline Central Tongu & $317(58.4)$ & 187(40.2) & & Ref. & Ref. \\
\hline Nkwanta South & $226(41.6)$ & 278(59.8) & & $2.08(1.62,2.68)<0.001$ & $2.77(1.56,4.90)<0.001$ \\
\hline Sex & & & $\begin{array}{l}67.35(< \\
0.001)\end{array}$ & & \\
\hline Male & $302(55.6)$ & 139(29.9) & & Ref. & Ref. \\
\hline Female & $241(44.4)$ & $326(70.1)$ & & $2.93(2.26,3.81)<0.001$ & $0.47(0.25,0.90) 0.023$ \\
\hline Age Group & & & $\begin{array}{l}18.70(< \\
0.001)\end{array}$ & & \\
\hline$<30$ & $140(25.8)$ & 156(33.6) & & Ref. & Ref. \\
\hline 30-39 & 139(25.6) & $131(28.1)$ & & $0.84(0.60,1.17) 0.320$ & $0.88(0.39,1.99) 0.767$ \\
\hline $40-49$ & 107(19.7) & $95(20.4)$ & & $0.79(0.55,1.14) 0.214$ & $1.99(0.81,4.89) 0.132$ \\
\hline $50+$ & 157(28.9) & $83(17.9)$ & & $0.47(0.33,0.67)<0.001$ & $3.10(1.25,7.68) 0.014$ \\
\hline Marital Status & & & $\begin{array}{l}33.91(< \\
0.001)\end{array}$ & & \\
\hline Married/Co-habiting & $406(74.8)$ & $411(88.4)$ & & Ref. & Ref. \\
\hline Divorced/Separated & $22(4.1)$ & $16(3.4)$ & & $0.71(0.37,1.38) 0.325$ & $0.69(0.20,1.99) 0.566$ \\
\hline Widowed & $32(5.9)$ & $11(2.4)$ & & $0.33(0.16,0.68) 0.002$ & $0.53(0.16,1.70) 0.293$ \\
\hline Never married & $83(15.2)$ & $27(5.8)$ & & $0.32(0.20,0.50)<0.001$ & $1.63(0.58,4.59) 0.352$ \\
\hline Educational level & & & $\begin{array}{l}43.37(< \\
0.001)\end{array}$ & & \\
\hline None & 162(29.8) & $124(26.7)$ & & Ref. & Ref. \\
\hline Primary & $91(16.8)$ & $106(22.8)$ & & $1.52(1.05,2.19) 0.024$ & $1.26(0.56,2.79) 0.570$ \\
\hline JHS & 161(29.6) & 186(40.0) & & $1.50(1.10,2.06) 0.010$ & $1.24(0.63,2.48) 0.526$ \\
\hline SHS/ & $89(16.4)$ & $43(9.2)$ & & $0.63(0.40,0.97) 0.037$ & $0.74(0.27,2.03) 0.563$ \\
\hline Tertiary & $40(7.4)$ & (1.3) & & $0.19(0.08,0.47)<0.001$ & $8.40(0.52,133.95) 0.132$ \\
\hline Occupation & & & $\begin{array}{l}46.09(< \\
0.001)\end{array}$ & & \\
\hline Unemployed & $44(8.1)$ & $31(6.7)$ & & Ref. & Ref. \\
\hline Trader & $61(11.2)$ & $78(16.8)$ & & $1.81(1.02,3.20) 0.040$ & $1.08(0.32,3.65) 0.898$ \\
\hline Farmer & 318(58.6) & $308(66.2)$ & & $1.37(0.84,2.23) 0.199$ & $1.12(0.37,3.36) 0.830$ \\
\hline Tradesman & $50(9.2)$ & $16(3.4)$ & & $0.45(0.21,0.93) 0.033$ & $0.46(0.09,2.20) 0.333$ \\
\hline Seamstress/hairdresser & $25(4.6)$ & $26(5.6)$ & & $1.47(0.72,3.02) 0.286$ & $0.25(0.04,1.47) 0.126$ \\
\hline Civil servant & $45(8.3)$ & $6(1.3)$ & & $0.18(0.07,0.49) 0.001$ & $0.04(0.0,0.67) 0.026$ \\
\hline NHIS Status & & & $\begin{array}{l}12.20(< \\
0.001)\end{array}$ & & \\
\hline Non-subscriber & 319 (58.7) & $222(47.7)$ & & Ref. & Ref. \\
\hline Subscriber & $224(41.3)$ & $243(52.3)$ & & $1.55(1.21,2.00)<0.001$ & $1.45(0.53,1.68) 0.872$ \\
\hline Home visit & & & $\begin{array}{l}129.94(< \\
0.001)\end{array}$ & & \\
\hline No & $241(44.4)$ & $54(11.6)$ & & Ref. & Ref. \\
\hline Yes & $302(55.6)$ & $411(88.4)$ & & $6.07(4.36,8.45)<0.001$ & $\begin{array}{l}27.47(11.51,65.54)< \\
0.001\end{array}$ \\
\hline Family Planning & & & $\begin{array}{l}374.78(< \\
0.001)\end{array}$ & & \\
\hline
\end{tabular}


Table 3 Influence of Socio-demographic characteristics and utilisation on satisfaction with CHPS (Continued)

\begin{tabular}{|c|c|c|c|c|c|}
\hline \multirow[t]{2}{*}{ Variables } & \multicolumn{2}{|l|}{ Level of Satisfaction } & \multirow{2}{*}{$\begin{array}{l}\text { Chi-square } \\
\left(x^{2}\right)(\boldsymbol{p} \text {-value) }\end{array}$} & \multirow[t]{2}{*}{ COR $(95 \% \mathrm{Cl}) \boldsymbol{p}$-value } & \multirow[t]{2}{*}{ AOR $(95 \% \mathrm{Cl}) \boldsymbol{p}$-value } \\
\hline & $\begin{array}{l}\text { Not satisfied }[\boldsymbol{N}=543] \mathrm{n} \\
(\%)\end{array}$ & $\begin{array}{l}\text { Satisfied }[\boldsymbol{N}=465] \mathrm{n} \\
(\%)\end{array}$ & & & \\
\hline No & $476(87.7)$ & $129(27.7)$ & & Ref. & Ref. \\
\hline Yes & $67(12.3)$ & $336(72.3)$ & & $\begin{array}{l}18.50(13.34,26.65)< \\
0.001\end{array}$ & $\begin{array}{l}23.54(11.97,46.29)< \\
0.001\end{array}$ \\
\hline Antenatal care services & & & $\begin{array}{l}332.70(< \\
0.001)\end{array}$ & & \\
\hline No & $533(98.2)$ & $225(48.4)$ & & Ref. & Ref. \\
\hline Yes & $10(1.8)$ & $240(51.6)$ & & $\begin{array}{l}56.85(29.63,109.07)< \\
0.001\end{array}$ & $\begin{array}{l}52.30(14.56,187.77)< \\
0.001\end{array}$ \\
\hline Skilled Delivery services & & & $\begin{array}{l}240.70(< \\
0.001)\end{array}$ & & \\
\hline No & $541(99.6)$ & $290(62.4)$ & & Ref. & Ref. \\
\hline Yes & $2(0.4)$ & $175(37.6)$ & & $\begin{array}{l}163.23(40.20,662.65)< \\
0.001\end{array}$ & $3.92(0.27,56.45) 0.314$ \\
\hline Postnatal care services & & & $\begin{array}{l}320.25(< \\
0.001)\end{array}$ & & \\
\hline No & $528(97.3)$ & $223(48.0)$ & & Ref. & Ref. \\
\hline Yes & $15(2.7)$ & $242(52.0)$ & & $\begin{array}{l}38.19(22.16,65.84)< \\
0.001\end{array}$ & $9.47(2.87,31.19)<0.001$ \\
\hline CWC and Immunisation & & & $\begin{array}{l}453.93(< \\
0.001)\end{array}$ & & \\
\hline No & 457 (84.2) & $79(17.0)$ & & Ref. & Ref. \\
\hline Yes & $86(15.8)$ & $386(83.0)$ & & $\begin{array}{l}25.96(18.58,36.26)< \\
0.001\end{array}$ & $\begin{array}{l}25.95(12.71,53.00)< \\
0.001\end{array}$ \\
\hline $\begin{array}{l}\text { Treatment for minor } \\
\text { ailments }\end{array}$ & & & $(<0.001)$ & & \\
\hline No & $214(39.4)$ & $63(13.6)$ & & Ref. & Ref. \\
\hline Yes & $329(60.6)$ & $402(86.4)$ & 84.07 & $4.15(3.02,5.69)<0.001$ & $\begin{array}{l}15.76(7.22,34.43)< \\
0.001\end{array}$ \\
\hline
\end{tabular}

\section{Conclusion}

While the level of CHPS utilisation is high, the level of satisfaction is low. The utilisation and satisfaction with CHPS are higher in Nkwanta South than in Central Tongu. Ghana may not be able to achieve the goals of universal health coverage by the year 2030 if current levels of utilisation and satisfaction with CHPS services persist. To accelerate progress towards the achievement of UHC with CHPS as the vehicle through which primary health care is delivered, we recommend that community members especially males should be given more public education on the relevance of CHPS by the GHS to increase their utilisation of CHPS among them. District/municipal/metropolitan and regional health directorates in Ghana should implement interventions geared towards improving the quality of CHPS services to increase community satisfaction. The GHS and the NHIA should sensitise communities as well as institute innovative strategies including extensive public education to increase subscription to the NHIS since it has implications for CHPS service utilisation and satisfaction.

\section{Supplementary information}

Supplementary information accompanies this paper at https://doi.org/10. 1186/s12913-020-05678-5.

\section{Additional file 1.}

\section{Abbreviations}

ANC: Antenatal Care; AOR: Adjusted Odds Ratio; $\mathrm{CHO}$ : Community Health Officer; CHPS: Community-Based Health Planning and Services; COR: Crude Odds Ratio; CWC: Child Welfare Clinic; FP: Family Planning; GEHIP: Ghana Essential Health Interventions Programme; GHS: Ghana Health Service; LMICs: Low- and Middle-Income Countries; NHIA: National Health Insurance Authority; NHIS: National Health Insurance Scheme; PHC: Primary Health Care; PNC: Postnatal Care; SDG: Sustainable Development Goal; SLDs: System Learning Districts; SPH: School of Public Health; UN: United Nations; UHAS: University of Health and Allied Sciences; UDS: University for Development Studies; UHC: Universal Health Coverage; WHO: World Health Organisation

\section{Acknowledgements}

We acknowledge the support of the other CHPS+ project collaborators; GHS, the Mailman School of Public Health Columbia University, USA, The University of Ghana Regional Institute of Population Studies, Ghana. Our appreciation also goes to the health workers and community members involved in the survey from the two SLDs; Central Tongu and Nkwanta South. 


\section{Authors' contributions}

MK, HA and JOG conceived the study. MK, HA and MA did the data analysis and wrote the methods section. MK, HA, MA, FYA, EM, EET, JK, GAA, NNA, and JOG were responsible for the initial draft of the manuscript. MA, FYA EM, EET, JK, GAA, NNA, LAB, JSA, RG, AAB, TL, JKAW, JFP, and JOG critically reviewed the manuscript for important intellectual content. MK, HA, MA, FYA, EM, EET, JK, GAA, NNA, LAB, JSA, RG, AAB, TL, JKAW, JFP, and JOG approved the final version of the manuscript for publication. MK, HA, MA, FYA, EM, EET, JK, GAA, NNA, LB, JSA, RG, AAB, TL, JKAW, JFP, and JOG have also agreed to be accountable for all aspects of the work in ensuring that questions related to the accuracy or integrity of any part of the work are appropriately investigated and resolved.

\section{Funding}

Funding for this study was provided by the Doris Duke Charitable Foundation, USA.

\section{Availability of data and materials}

The datasets used and/or analysed during the current study available from the corresponding author on reasonable request.

\section{Ethics approval and consent to participate}

Ethics approval for this study was obtained from the GHS Ethics Review Committee (GHS-ERC) with number GHS-ERC: 04/01/2017. Consent to participate in the study was also obtained through written informed consent forms from the participants.

\section{Consent for publication}

Not Applicable.

\section{Competing interests}

The authors declare that they have no competing interests.

\section{Author details}

'School of Public Health, University of Health and Allied Sciences, Hohoe, Ghana. ${ }^{2}$ Volta Regional Health Directorate, Ghana Health Service, Ho, Ghana. ${ }^{3}$ Regional Institute of Population Studies, University of Ghana, Legon, Ghana. ${ }^{4}$ Policy Planning Monitoring and Evaluation Division, Ghana Health Service, Accra, Ghana. ${ }^{5}$ Mailman School of Public Health, Columbia University, New York, USA. ${ }^{6}$ Office of the Vice-Chancellor, University of Health and Allied Sciences, Ho, Ghana.

Received: 30 May 2019 Accepted: 20 August 2020

Published online: 09 September 2020

\section{References}

1. Afari-Asiedu S, Asante KP, Senah K, Abdulai MA, Afranie S, Mahama E, et al. Volunteering for health Services in the Middle Part of Ghana: in whose interest? Int J Health Policy Manag. 2018;7(9):836.

2. World Health Organisation. Primary health care. Geneva: WHO; 1978

3. Aid C. Assessment of primary health Centres in selected states of Nigeria: summary report of findings from Christian Aid supported communities in Anambra, Benue, Kaduna, plateau states and the Federal Capital Territory (FCT). Abuja: Christian Aid; 2015.

4. Awoonor-Williams JK, Phillips JF, Bawah AA. An overview of GEHIP and the CHPS+ proposal. In: Presentation at a CHPS+ project protocol planning meeting, August; 2016. p. 18-20.

5. World Health Organisation. Primary health care, universal health coverage and the Astana Global Conference; 2018. https://www.unicef.org/health/ index_primary-health-care.html.

6. Kweku M, Amu H, Adjuik M, Manu E, Aku FY, Tarkang EE, et al. Community Involvement and Perceptions of the Community-Based Health Planning and Services (CHPS) Strategy for Improving Health Outcomes in Ghana: Quantitative Comparative Evidence from Two System Learning Districts of the CHPS+ Project. Adv Public Health. 2020;7:1-12

7. Kweku M, Amu H, Awolu A, Adjuik M, Ayanore MA, Manu E, et al. Community-based health planning and services plus programme in Ghana: a qualitative study with stakeholders in two systems learning districts on improving the implementation of primary health care. PLoS One. 2020;15(1): e0226808.
8. Phillips JF, Awoonor-Williams JK, Bawah AA, Nimako BA, Kanlisi NS, Sheff MC, Asuming PO, Kyei PE, Biney A, Jackson EF. What do you do with success? The science of scaling up a health systems strengthening intervention in Ghana. BMC Health Serv Res. 2018;18(1):484.

9. Amu H, Dickson KS. Health insurance subscription among women in reproductive age in Ghana: do socio-demographics matter? Heal Econ Rev. 2016;6(1):1-8.

10. Jehu-Appiah C, Aryeetey G, Spaan E, De Hoop T, Agyepong I, Baltussen R. Equity aspects of the National Health Insurance Scheme in Ghana: who is enrolling, who is not and why? Soc Sci Med. 2011;72(2):157-65.

11. David JL, Kaplan HB. Gender, social roles and health care utilisation. Appl Behav Sci Rev. 1995;3(1):39-64.

12. Sharma A, Prinja S, Aggarwal AK. Measurement of health system performance at district level: A study protocol. J Public Health Res. 2017;6(3): 175-83.

13. Kok MC, Broerse JE, Theobald S, Ormel H, Dieleman M, Taegtmeyer M. Performance of community health workers: situating their intermediary position within complex adaptive health systems. Hum Resour Health. 2017; 15(1):59.

14. Abdul-Rahaman Y. Factors influencing utilisation of Communiy-based health planning and services in BunkpuruguYunyoo Districtin northern region of Ghana (doctoral dissertation). Legon: University of Ghana; 2018.

15. Wiru K, Kumi-Kyereme A, Mahama EN, Amenga-Etego S, Owusu-Agyei S. Utilisation of community-based health planning and services compounds in the Kintampo north municipality: a cross-sectional descriptive correlational study. BMC Health Serv Res. 2017;17(679):1-11.

16. Wood EA, Esena RK. Assessment of Community Utilisation of CHPS Services in Komenda-Edina-Eguafo-Abrem (KEEA) Municipality in the Central Region of Ghana. J Biol Agric Healthc. 2013;3(8):63-81.

17. Akumatey, S. Bad roads in Northern Volta is a Health Risk. (25th October 2017) GNA article. Amissh, B. Primary health care in Ghana; 2018. https:// www.ghanaweb.com/GhanaHomePage/NewsArchive/Primary-health-carein-Ghana-647657.

18. University of Health and Allied Sciences (UHAS). General information on UHAS; 2018. https://www.uhas.edu.gh/en/about-us/overview.html.

19. Ghana Statistical Service (GSS). 2010 Population and housing census: Regional analytical report: Volta Region. Accra: GSS; 2013.

20. Ghana Statistical Service (GSS). Projected population by district and sex, Volta Region, 2010, 2015-2020; 2018.

21. Cochran WG. Sampling techniques. 3rd ed. New Jersey: Wiley; 1977.

22. Taber KS. The use of Cronbach's alpha when developing and reporting research instruments in science education. Res Sci Educ. 2018;48(6):1273-96.

23. Nyonator FK, Awoonor-Williams JK, Phillips JF, Jones TC, Miller RA. The Ghana Community-based Health Planning and Services Initiative: fostering evidence-based organizational change and development in a resourceconstrained setting, Policy Research Division Working Paper no. 180. New York: Population Council; 2003.

24. Setordjie I. Deplorable Nkwanta South roads hampering economic activities; 2018. https://www.myjoyonline.com/business/2018/June-26th/deplorablenkwanta-south-roads-hampering-economic-activities.php.

25. Annim SK, Mariwah S, Sebu J. Spatial inequality and household poverty in Ghana. Econ Syst. 2012;36(4):487-505.

26. Amu H, Sekyi DK. Effects of Spatial Location and Household Wealth on the Utilisation of Skilled Birth Attendants at Delivery Among Women in Rural Ghana. Ghana J Geogr. 2018;10(1):58-77.

27. Chapman AR. Assessing the universal health coverage target in the sustainable development goals from a human rights perspective. BMC Int Health Hum Rights. 2016;16(33):1-9.

28. Noh JW, Kim KB, Park H, Kwon YD. Gender differences in outpatient utilisation: a pooled analysis of data from the Korea Health Panel. J Women's Health. 2017;26(2):178-85.

29. Amu H, Dickson KS, Kumi-Kyereme A, Darteh EK. Understanding variations in health insurance coverage in Ghana, Kenya, Nigeria, and Tanzania: Evidence from demographic and health surveys. PLoS One. 2018;13(8): e0201833.

30. Kumi-Kyereme A, Amu H, Darteh EKM. Barriers and motivations for health insurance subscription in Cape Coast, Ghana: a qualitative study. Arch Public Health. 2017:75(24):1-10.

31. Dalinjong PA, Wang AY, Homer CS. Has the free maternal health policy eliminated out of pocket payments for maternal health services? Views of 
women, health providers and insurance managers in northern Ghana. PLoS One. 2018;13(2):e0184830.

32. Sakeah E, McCloskey L, Bernstein J, Yeboah-Antwi K, Mills S, Doctor HV. Can community health officer-midwives effectively integrate skilled birth attendance in the community-based health planning and services program in rural Ghana? Reprod Health. 2014;11(90):1-13.

33. Azhar A, Rahman MM, Arif MT. Satisfaction on primary health care services in sarawak, malaysia: evidence from a cross-sectional community based study. Population. 2016;16(3):267-73.

\section{Publisher's Note}

Springer Nature remains neutral with regard to jurisdictional claims in published maps and institutional affiliations.

Ready to submit your research? Choose BMC and benefit from:

- fast, convenient online submission

- thorough peer review by experienced researchers in your field

- rapid publication on acceptance

- support for research data, including large and complex data types

- gold Open Access which fosters wider collaboration and increased citations

- maximum visibility for your research: over $100 \mathrm{M}$ website views per year

At $\mathrm{BMC}$, research is always in progress.

Learn more biomedcentral.com/submissions 